\title{
AÇÃO PEDAGÓGICA DIALÓGICA: DESAFIO PARA SUPERAR A RACIONALIDADE DISCIPLINAR*
}

\author{
Maria da Anunciação Pinheiro Barros Neta, \\ da Universidade Federal de Mato Grosso (UFMT).
}

\begin{abstract}
Resumo: O trabalho apresenta resultados da pesquisa sobre possível efetivação da ação educativa de cunho interdisciplinar no curso de Pedagogia. Após a introdução, retoma, de forma sucinta, indicações teóricas de Weber e Tragtenberg sobre o processo de racionalização moderno e suas implicações na educação disciplinar. Com base na investigação qualitativa fenomenológica, descreve as informações colhidas das alunas entrevistadas e, como resultado, compreende e interpreta que é muito difícil construir a ação pedagógica de cunho interdisciplinar no interior da instituição ancorada na disciplinarização. Finaliza apresentando breve síntese da análise da pesquisa e aponta estratégias para inverter o movimento disciplinar na educação.

Palavras-Chave: Racionalidade disciplinar. Pedagogia burocrática. Interdisciplinaridade. Ações pedagógicas dialógicas.
\end{abstract}

INTRODUÇÃO

São muitos os problemas no ensino brasileiro. A maioria dos estudantes perdeu o uso da linguagem, mostra-se despreparada para a leitura, análise ou discussão de um texto. A cultura dominante tem imposto o uso generalizado de slogans, da linguagem imperativa e denotativa. Quanto ao uso da linguagem, faltam às pessoas, por vezes até aos professores, mas, sobretudo aos alunos, sequência, encadeamento de pensamentos, ou seja, a capacidade de traduzir conceitualmente seus problemas e angústias, suas experiências, sentimentos e intuições.

Também se considera bastante preocupante o fato de parcela significativa de estudantes buscar o ensino superior não como oportunidade

\footnotetext{
* Artigo recebido em 01/08/2012 e aprovado em 22/01/2013.
} 
para obter formação consistente para a vida profissional, social e pessoal, mas, principalmente, para obter certificado e/ou diploma que lhe possibilite entrada bem rápida no mercado de trabalho, dado que as crises econômicas ampliam a faixa dos desempregados e a frustração decorrente das expectativas não realizadas incide sobre as conflitos pessoais e sociais.

É evidente que não se está aqui defendendo o ensino que desconsidere a formação profissional. O que se questiona é o entendimento que se tem desse conceito, uma vez que a formação profissional não pode ser reduzida a um diploma, nem tampouco significar apenas apreensão aligeirada de conhecimentos técnicos para atuação em atividades e funções ora exigidas na sociedade. Deve-se contemplar uma formação mais abrangente na qual estejam presentes, também, conhecimentos filosóficos, científicos, éticos e estéticos que valorizam a humanização das pessoas.

Decerto, é notória a falta de motivação da maioria dos alunos para o ato de estudar, debater e compreender os subsídios teóricos e metodológicos propostos nos programas curriculares. É deveras desestimulante constatar, no dia a dia, que - sem as amarras autoritárias da pedagogia burocrática - boa parte dos alunos não cumpriria o número de horas exigido e não realizaria as atividades necessárias ao curso. Observa-se que a nota (preferencialmente alta) transforma-se em fonte de preocupação básica e busca obsessiva durante todo o processo educativo.

Diante do exposto, questiona-se: Que sentido tem a educação para o educando? Por que grande parte dos alunos não se sente motivada para apreender os conteúdos curriculares? Tais conteúdos curriculares têm a ver com a vida e a realidade concreta do educando? Qual a razão ou razões para tanto desinteresse, indiferença e desmotivação de uma maioria significativa, expressa no processo pedagógico? A razão está na instituição escolar? No programa curricular? Na relação educando-educador? Na metodologia adotada pelo educador? Na disciplinarização do ensino?

Difícil responder, pois os problemas educacionais são oriundos de diversos fatores (e por eles determinados) que interagem no interior da sociedade complexa ao extremo. Contudo, a questão da racionalidade disciplinar continua sendo discutida e apontada por inúmeros especialistas e educadores como um dos graves problemas a ser enfrentado nas escolas e universidades.

Um grupo considerável de autores - a exemplo de Fazenda (1979, 1991, 1994), Freire (1986, 2005), Gadotti (1993), Gallo (1994, 1996), Gonçalves (1996), Gusdorf (1967), Japiassu (1976), Freitas (1989), Frigotto (1995), Lück (1994), Pombo (2003, 2004), Moraes (2002), Morin (2005), Piaget (1973), Vygotsky (1986), Thiesen (2008), dentre outros -, preocupado em apresentar 
uma alternativa à disciplinarização do saber causada por uma epistemologia de caráter positivista, tem investigado a ação interdisciplinar sob diferentes enfoques, visando possibilitar o diálogo entre os diversos saberes científicos que compõem o sistema curricular e, portanto, contemplando a superação da fragmentação do conhecimento, tanto em nível de currículo quanto em nível de pesquisa.

Nessa direção, liderados pela coordenação de graduação do curso de Pedagogia da Universidade Federal de Mato Grosso, um grupo de professores, quando de algumas revisões no âmbito curricular em 2006, propôs e inseriu a disciplina Projetos Integradores de Prática Docente (90 h/a); um espaço para o trabalho coletivo potencialmente capaz de gerar interdisciplinaridade, articulando, em nível teórico e prático, os três núcleos de estudo que compõem o currículo: estudos profissionais gerais, estudos profissionais, estudos e atividades interdisciplinares. Isso porque a abordagem das disciplinas curriculares vinha (e ainda vêm) sendo instituída de maneira fragmentada. Essa forma desarticulada de trabalhar os vários domínios do saber não leva o aluno a pensar o real em que ele está inserido e a perceber, desse lugar, a relação do mundo social e cultural, entendendo cada fenômeno observado ou vivido a partir da rede de relações que lhe confere múltiplos sentidos.

De acordo com esse entendimento, a ideia não seria abandonar os conhecimentos específicos das diferentes ciências, nem tampouco dilui-los em recortes superficiais, mas trabalhar todos os enfoques disciplinares de modo interligado, para que o aluno possa construir uma consciência mais ampla da realidade, na qual os fenômenos sociais e educacionais sejam vistos, observados e entendidos na sua complexidade e de forma contextual. Isso situaria o educando no campo mais extenso do conhecimento, conduzindo-o, efetivamente, a tomar parte e interagir na sociedade, atuando e interferindo sobre ela.

Essa questão constitui indicativo pertinente para a compreensão das práticas pedagógicas que se estabelecem na formação universitária, especialmente na UFMT, sobretudo porque, em muitas ocasiões, tem-se verificado que diversas tentativas de inovação do trabalho educativo no âmbito interdisciplinar resultam no fortalecimento da desarticulação dos saberes epistemológicos e pedagógicos, do trabalho individualizado e dos processos e relações educacionais antidialógicas.

Nessa medida, após a introdução, este trabalho retoma, de forma sucinta, a explicação, formulada por Weber (1864-1920), acerca do processo de racionalização que originou o saber especializado, e indicações teóricas 
de Tragtenberg (1929-1998) para melhor compreender as implicações da racionalização disciplinar no sistema pedagógico.

Em um terceiro momento, com base na percepção desta pesquisadora e informações colhidas das alunas entrevistadas, pretende-se descrever e interpretar uma possível efetivação da ação educativa de cunho interdisciplinar no curso de Pedagogia.

Finaliza apresentando breve síntese da análise da pesquisa e apontando a necessidade de construir ações dialógicas e democráticas nos espaços escolares, em geral, e na universidade, em particular.

\section{DISCIPLINARIDADE: PODER E CONTROLE NO PROCESSO PEDAGÓGICO}

O ponto central da análise de Weber é a racionalidade como atributo fundamental do processo de burocratização. Em sua teoria da dominação, o autor faz distinção entre o que ele considera poder, dominação e disciplina.

Segundo Weber (1994), poder significa a probabilidade de alguém sobrepor a sua vontade em uma relação social, independente de resistência e independente da justificativa dessa probabilidade. Todavia, percebe-se que o conceito de poder é sociologicamente amorfo. Por isso, ele não se mostra interessado nesse poder que considera muito abrangente, que compreende a totalidade, mas, sim, em um tipo específico de poder a que chama dominação. Conforme Weber, o conceito sociológico de dominação deve ser mais preciso e só pode significar a probabilidade de encontrar obediência a uma determinada ordem. A situação de dominação está ligada à presença efetiva de alguém mandando de forma eficaz em outros, mas não necessariamente à existência de um quadro administrativo.

Nessa perspectiva, Weber (1994) destaca a burocracia como administração por especialistas ou profissionais. Ele assegura que as formas modernas de administração se caracterizam pela importância atribuída à especialização. O fundamento primeiro da administração burocrática reside no papel do conhecimento. A questão é sempre a de quem controla o aparato existente, $\mathrm{e}$ tal controle é limitado para as pessoas que são especialistas. Ou seja, a administração burocrática significa, em essência, o exercício do controle baseado no conhecimento. Conhecimento técnico de determinada área, acumulado pelo tempo de serviço. Esse é o aspecto que a torna especificamente racional.

Assim, Weber entende burocracia como organização que tem duas faces: de um lado, ela é organização baseada na especialização. Nesse tipo de organização, recorre-se à obediência como meio para a realização de um fim, isso é, o indivíduo obedece porque a norma ou ordem dada é percebida como a melhor forma para a consecução de determinado objetivo. De outro 
lado, a burocracia é organização baseada na disciplina, na qual a obediência corresponde a um fim em si mesmo, ou seja, o indivíduo obedece à ordem, buscando se isentar de qualquer julgamento de valor, principalmente pela posição de poder de quem ordena. Nesse caso, o conteúdo da ordem não está posto em discussão.

Weber afirma que a burocracia, baseada na razão e no direito, manifesta-se com o capitalismo avançado e com o nascimento do Estado moderno. E, segundo ele, só é possível definir sociologicamente o Estado moderno, assim como toda a associação política, por um meio peculiar que é o da coação física. Vejamos como ele define o Estado e as associações.

O Estado, do mesmo modo que as associações políticas historicamente precedentes, é uma relação de dominação de homens sobre homens, apoiada por meio da coação legítima (quer dizer, considerada legítima). Para que ele subsista, as pessoas dominadas têm que se submeter à autoridade invocada pelas que dominam (WEBER, 1999).

Para Weber, a dominação ocorre porque o governante, que impõe sua vontade, acredita ter o direito de praticar o poder, e o governado crê ter o dever de submeter-se e executar as ordens do governante. Por isso, a crença (de governantes e governados) é imprescindível para justificar o exercício do poder.

Tal dominação caracteriza-se por ser fundada na obediência à ordem impessoal, objetiva e legitimamente instituída (estatutos, normas escritas) e na obediência aos superiores determinados por ela, devido à legalidade formal de suas disposições dentro do seu campo de vigência. Esse tipo de dominação é identificado pela crença na validade da justiça da lei, das ordens estabelecidas e pelo direito de autoridade dos que são nomeados para exercer a dominação. Ou seja, a validade do poder racional e legal baseia-se em normas definidas por lei de forma racional. A crença na justiça das leis é o sustentáculo da legitimação. $O$ indivíduo obedece às leis, porque acredita que elas são decretadas por um processo autêntico, correto, escolhido tanto pelos governados quanto pelos governantes. Além disso, o governante é visto como uma pessoa que alcançou tal posição exclusivamente por procedimentos legais (como nomeação, concursos, eleições etc.) e é em virtude de sua posição alcançada que ele exerce o poder, dentro dos limites fixados pelas regras e regulamentos legais. Nesse tipo de dominação predomina o formalismo, a existência de um estatuto que contém um sistema de regras e princípios com força de leis. Esse sistema de regras rege a associação ou a instituição pública ou privada e os funcionários obedecem à ordem impessoal estabelecida, de modo racional, formal. 
A organização administrativa que está em correlação com a dominação legal é chamada burocracia. A burocracia é a organização típica da sociedade moderna democrática, e os funcionários são chamados burocratas, os quais confiam nas leis e na ordem legal. As funções e relações entre os funcionários são instituídas por regras que independem das pessoas. Tais regras impessoais, que põem em evidência o caráter da burocracia, ocasionam uma hierarquia de cargos, cada um com determinados deveres e direitos, e impessoalidade na seleção dos funcionários. Nesse tipo de dominação, deve-se obedecer, exclusivamente, à regra determinada em estatuto que estabelece, ao mesmo tempo, a quem e em que medida se deve obedecer.

Segundo Weber (1999), toda organização de dominação que requer a administração permanente necessita da obediência dos governados diante dos governantes e, para conseguir tal obediência, exige um quadro administrativo de pessoal e recursos administrativos materiais para efetivar a coação física.

A burocracia surgiu na época da Revolução Industrial, quando ocorreu nova organização do capitalismo e do trabalho. A lógica do sistema da indústria nutre-se na necessidade de inovação constante, de especialização crescente, de organização hierárquica do trabalho, de divisão e fragmentação das tarefas. Trata-se de processo impessoal, movido pela dinâmica competitiva, responsável pela alienação, por uma forma cultural que faz da especialização crescente exigência de autossustentação (SOUZA, 1999).

A racionalidade de meios resulta da especialização crescente em razão do aspecto fragmentário do trabalho. $\mathrm{O}$ especialista, realizando somente fração do trabalho, não consegue conhecer seu fim. A especialização é tornada indispensável. A dinâmica do processo é a competitividade, que se encontra presente não apenas no universo econômico, mas também no universo político, no universo social, cultural artístico e intelectual (SOUZA, 1999).

A burocracia revela estreita relação com a educação, uma vez que o sistema escolar passou a ter papel fundamental na formação de indivíduos técnicos e profissionais em várias e diferentes especialidades, visando suprir a demanda exigida pelo mercado de trabalho moderno. Por essa razão, foram construídas numerosas escolas: dentre outras, escolas práticas, escolas de comércio e de indústria, escolas profissionais e escolas de ensino técnico. Todas com o fim de qualificar o trabalhador (de todas as classes produtoras) em distintos campos de conhecimento, transformando, inclusive, a população formada por mulheres e crianças em mão de obra disponível para as necessidades do mercado. 
Segundo Tragtenberg, a burocracia estrutura-se nas instituições escolares da mesma forma como se apresenta na empresa capitalista e, também, na área da administração pública. Sua função primordial é organizar, dominar e controlar. A universidade, por exemplo, não é só uma instituição dominante. Ela é também uma instituição de dominação, "burocratizada, montada como estrutura de controle, pois em nome da organização, ela tem como religião o culto da hierarquia, isso é, o culto da distribuição desigual do poder, onde poucos podem muito e muitos não têm voz" (TRAGTENBERG, 2004, p. 210)

No plano mais amplo, o Ministério da Educação impõe diretrizes educacionais à universidade e, no plano mais específico, a universidade divide os docentes em escalões de poder. Desse modo, professores são investidos em cargos de reitores, pró-reitores, diretores de institutos ou faculdades, chefes de departamentos, coordenadores de graduação e pós-graduação. Cada um desses escalões demarca um nível de poder que procura aumentar e preservar. A hierarquia também se manifesta na classificação de alunos e professores por escalões: mestres, doutores, pós-doutores, livres-docentes (e não docentes livres), e alunos de graduação e pós-graduação (2004).

Em geral, mesmo sem o autoritarismo dos anos 1970, tais escalões de poder procuram executar as decisões e determinações superiores a partir da racionalidade de meios, isso é, de forma racional, metódica, impessoal, eficiente e sem questionamento dos fins. Por isso, normalmente, as novas e novíssimas propostas educacionais acionadas pelo Ministério da Educação são aprovadas pelos escalões de poder com absoluta desconsideração pelo pensamento da comunidade acadêmica. Sem entrarmos no mérito das propostas, o que se questiona é a necessidade de sua aprovação às pressas, sem oferecer aos seus maiores interessados (sociedade, em geral, e professores e alunos, em particular) a oportunidade de analisar, debater, deliberar.

Essa organização hierárquica estrutura o controle, impede a autonomia universitária, a liberdade e participação efetiva de professores e alunos nas decisões políticas educacionais (tão necessárias à democracia), na medida que fazem consultas formais aos departamentos e demais órgãos colegiados; dessa forma, suprimem a voz da maioria, eliminam, a priori, a livre luta entre as opiniões e acatam rapidamente a voz de poucos investidos nos escalões de poder.

A universidade se esclerosa na burocratização na medida que não há participação do aluno, professor e funcionário nas decisões básicas. Isso leva a baixar o nível de motivação no aluno ao receber conhecimentos, no professor 
em transmiti-los e no funcionário em executar suas funções. (TRAGTENBERG, 2004, p. 75)

No plano mais específico pedagógico, a pedagogia burocrática alimenta o sistema disciplinar, posto que os meios de dominação e controle sobre o aluno ainda continuam indispensáveis e os fins pedagógicos, muitas vezes, questionáveis. Por isso, o Diário de Classe para o registro de faltas e notas nunca foi abolido.

O sistema de exames faz parte da pedagogia burocrática no sentido weberiano, que se converte em uma pedagogia repressiva, quando o aluno é submetido a avaliações pelo sistema de notas e troca de informações entre professores a respeito de alunos e cumprimento rígido de programa com objetivos comportamentais. (TRAGTENBERG, 2004, p. 72)

\section{Projetos Integradores de Prática Docente: ensaio para romper fron- TEIRAS DISCIPLINARES.}

Tem havido enorme esforço de educadores no sentido de construir ações educativas democráticas, com vista a desenvolver projetos que articulem os vários domínios do saber, levem o aluno a pensar o real em que está inserido e a perceber, daí, a relação do mundo social e cultural, entendendo cada fenômeno observado ou vivido, a partir da rede de relações que lhe confere múltiplos sentidos.

O percurso dessa pesquisa qualitativa fenomenológica - apoiada em Lüdke e André (1986), Bogdan e Biklen (1984), Martins (1984), Bicudo e Espósito (1997), Merleau-Ponty (1971), Rezende (1990) - realizou-se nos anos de 2007 e 2008 junto às alunas do $1^{\circ}$. ano (turno matutino) do curso de Pedagogia.

Havia a preocupação com a formação da consciência crítica, e a intenção maior era passar para as alunas a visão de mundo integrado, em que os saberes (filosofia, antropologia, história, sociologia, psicologia e linguística) estudados nessa série se articulassem, não constituindo em esferas estanques de saberes.

Para tanto, a ideia central era que as alunas realizariam pesquisas e os professores iriam contribuir para que os aspectos investigados fossem percebidos e compreendidos de forma interligada. O coordenador de cada série teria a responsabilidade de planejar e desenvolver a referida disciplina em conjunto com os demais colegas, a fim de estabelecer o diálogo entre as 
diferentes áreas de conhecimento, visando possibilitar a construção da visão de mundo mais orgânica e contextualizada.

A primeira e fundamental dificuldade se impôs logo no início, quando foi marcada uma reunião com os professores para organizar o trabalho coletivo. Grande parte manifestou resistência a essa proposta educativa: uns por não acreditarem que ela produziria efeitos positivos na formação; outros por estarem se dedicando a outras problemáticas educacionais, consideradas, por eles, mais relevantes para os dias atuais; os demais professores não manifestaram qualquer justificativa.

Apesar da resistência da maioria dos professores à nova diretriz educacional e, consequentemente, da impossibilidade do trabalho conjunto, a coordenação do curso entendeu ser interessante insistir na tentativa de estabelecer a articulação entre os saberes e entre ensino e pesquisa.

Por conseguinte, desenvolveu-se a proposta de interrelacionar as diversas disciplinas a partir dos problemas investigados. Participaram dessa pesquisa 40 alunas no ano de 2007, somando-se mais 40 no ano de 2008, totalizando 80 alunas nos dois anos. As pesquisas sobre diferentes aspectos da realidade tiveram como base o tema geral, denominado "A sociedade e o ato educativo".

No ano de 2007 e 2008, os grupos foram orientados a montar projetos. As problemáticas surgiram do interesse dos próprios alunos sobre o que estudar (objeto da investigação) e sobre como estudar (a metodologia). Acredita-se que esses dois aspectos foram, por assim dizer, animadores para a realização das pesquisas.

Divididas em pequenos grupos, realizaram o planejamento e as atividades práticas. Durante todo o processo, procedeu-se à orientação das alunas sobre os objetivos da disciplina e das pesquisas a serem alcançados, fornecendo sugestões e estímulo diante dos empecilhos para dar maior profundidade e dimensão a esse esboço de interdisciplinaridade.

Propôs-se que a linha metodológica de trabalho possibilitasse a maior participação no processo de experiência investigativa. Para tanto, orientouse o trabalho de pesquisa de forma socializada e individualizada, o grupo e a pessoa, o todo e a parte, ambos tomados em sua totalidade e também passíveis de fragmentações para efeito de análise crítica e de reflexão.

As diferenças individuais foram levadas em conta e o desenvolvimento em direção aos objetivos propostos avaliados em função do ritmo das alunas com relação à aprendizagem e ao interesse, o que significou a tentativa de aplicar diferentes técnicas para perceber com quais delas as alunas mais se identificavam. Procurou-se motivá-las a perceberem, em seu aprendizado, um 
sentido maior, não restrito simplesmente à nota do trabalho ou à aprovação final. Talvez por isso, grande parte mostrou-se bastante envolvida com o que estava pesquisando.

O processo foi todo acompanhado e resultou que, diante das condições objetivas e subjetivas, os grupos realizaram razoáveis, bons e, até, excelentes trabalhos, mas (como era também de se esperar) não foram além dos recortes disciplinares. Em grande parte dos trabalhos não houve compreensão de uma vivência investigativa interdisciplinar.

Do ponto de vista da pesquisa, alguns grupos conseguiram fazer uma reflexão mais detida sobre os objetos pesquisados. Outros, no entanto, não conseguiram de modo satisfatório. Alguns por imaturidade e inexperiência (o que é absolutamente justificável), e outros, uma minoria, por negligência e descompromisso com o estudo.

Buscou-se, também, não controlar e, sim, orientar todos os grupos, alertando para os objetivos a serem alcançados, trabalhando junto com elas, fornecendo-lhes sugestões e estímulo diante dos entraves e mostrando sempre que elas eram capazes. Na maioria dos grupos, surgiu a disciplina do estudo da própria atividade de pesquisa.

Algo bem estimulador para as alunas foi a disponibilidade de alguns professores em colaborar com os grupos no sentido de responder questionários, conceder entrevistas, fornecer materiais e sugestões para o desenvolvimento e enriquecimento dos trabalhos.

No final da disciplina, aplicaram-se entrevistas semiestruturadas, com o objetivo de compreender, com base nos referenciais teóricos escolhidos, as percepções das alunas acerca do processo que fora desenvolvido. No geral, as informações colhidas confirmaram, sem distinções expressivas entre os anos de 2007 e 2008, que sem o trabalho conjunto dos professores não seria possível provocar, de forma significativa, a compreensão dos conhecimentos e da realidade de modo contextual e interdisciplinar.

Foge ao objetivo deste artigo descrever com detalhes todas as questões feitas nas entrevistas. O presente texto limita-se a comentar apenas quatro questões e suas respectivas respostas por serem recorrentes.

Questionadas sobre a função da disciplina Projetos Integradores de Prática Docente no $1^{\circ}$. ano de Pedagogia, $60 \%$ responderam: desenvolver projetos integrando teoria e prática e articulando todas as disciplinas da série, uma vez que a divisão do conhecimento em especialidades é somente para facilitar o entendimento, devido à amplitude dos conteúdos e informações; $40 \%$ disseram não saber responder pela falta de clareza quanto ao papel da disciplina. 
Essas informações, colhidas nas entrevistas, serviram para explicitar a contradição que permeia o processo pedagógico e tornaram possível a cada aluna, por meio do diálogo pessoal e coletivo, descortinar algumas contradições. Por um lado, demonstrou-se que grande parte das alunas traz consigo concepções da cultura dominante ainda muito arraigadas. Nas respostas sobre a função da disciplina, Projetos Integradores de Prática Docente, foi detectado um paradoxo. No primeiro momento, elas afirmaram que a função da disciplina era integrar teoria e prática e articular os diversos saberes estudados na série, mediante projetos de pesquisa; $\mathrm{e}, \mathrm{em}$ seguida, assumiram, com coerência, a perspectiva disciplinar, uma vez que reproduziram a ideia da necessidade de dividir o objeto em infinitas partes para melhor compreendê-lo.

Questionadas sobre a efetivação da ação interdisciplinar por meio dos projetos, $60 \%$ responderam que não perceberam o conhecimento de forma contextual, interligado a partir das várias especialidades de saber. Por outro lado, 30\% da amostra (mesmo sem o trabalho conjunto dos professores) responderam que conseguiram perceber, no projeto, alguma articulação entre antropologia, sociologia e filosofia da educação; $10 \%$ justificaram não ter claro uma resposta.

Nas narrativas das alunas, evidencia-se que a maioria não percebeu ação educativa interdisciplinar, como mostram os trechos a seguir colhidos das entrevistas:

Deu para perceber muito bem a distância entre a proposta do curso e sua real efetivação, pois cada professor vinha e desenvolvia o conteúdo de sua disciplina de forma isolada das demais. Não houve colaboração na orientação da realização dos projetos voltados para o conhecimento interdisciplinar.

Na mesma perspectiva, outra entrevistada se manifestou da seguinte forma: "Eu me esforcei, dei o máximo de mim, mas não consegui ver o objeto pesquisado na perspectiva interdisciplinar". Na mesma direção, outra entrevistada se expressou da seguinte forma: "Todo o mundo viu que o coordenador da série se esforçou muito, mas não conseguiu realizar esse objetivo. Tem muita gente que disse que entendeu, mas será que entendeu mesmo?" Do mesmo modo afirmou outra aluna: "Verdadeiramente, não. Não consegui visualizar o conhecimento de modo interdisciplinar nem em nosso projeto e nem com base nos conteúdos das disciplinas, mas sei que terei bastante tempo para aprender".

Entretanto, há relatos de outras entrevistadas que atestam ter visualizado o conhecimento interdisciplinar. Os fragmentos a seguir indicam isso: 
"Sim, consegui verificar. A conscientização dessas teorias da aprendizagem me possibilitou a saída do senso comum, para a prática libertadora, pensar/ agir, teoria /prática, dimensões inseparáveis para vivermos na escola da vida".

De acordo com outra entrevistada: "Consegui visualizar, em nosso projeto, elementos dos saberes sobre filosofia, antropologia e sociologia, os quais me remeteram a desenvolver o pensamento crítico e enxergar a conexão entre meu viver cotidiano e sociedade".

Nesse sentido, mais uma entrevistada assim se reportou: "No nosso projeto, foi possível perceber interdisciplinaridade somente de conhecimentos filosóficos, antropológicos e sociológicos, mas acho que é porque os professores sempre tentavam nos fazer enxergar a relação entre essas matérias".

Esses dados revelaram muito bem as contradições em nosso processo pedagógico: por um lado, as informações revelaram que a educação não se realiza de forma linear, homogênea e simples, uma vez que muitas alunas verificaram nos projetos pontos de conexão entre algumas disciplinas. Isso mostrou ainda, a importância e validade dos esforços e desejos, mesmo que solitários, de alguns professores que insistem na tentativa de desconstruir a racionalidade disciplinar; por outro lado, as informações mostraram que o trabalho educativo na universidade continua sendo desenvolvido de forma compartimentada. Com efeito, salvo raras exceções, o que se presenciou e se tem presenciado regularmente é que a maioria dos docentes conduz suas disciplinas de forma individualizada, sem nenhuma preocupação em dialogar com os demais colegas para realização de um trabalho pedagógico interdisciplinar. Intui-se que a aparente posse do conhecimento parcelar, como tendo sentido orgânico por si mesmo, retira a necessidade de os próprios docentes estabelecerem nexos com outras áreas epistemológicas, bem como com o quadro geral no qual circunscrevem os conhecimentos que reproduzem.

Essa questão é confirmada, quando se questionam os aspectos positivos e negativos da disciplina: mais de $70 \%$ das alunas entrevistadas responderam que a disciplina foi muito interessante do ponto de vista da pesquisa, pois em geral as aulas são monótonas, enfadonhas, desinteressantes e cansativas; contudo lamentaram a ausência do trabalho coletivo que, segundo elas, poderia ter gerado compreensão mais abrangente e crítica dos aspectos educacionais investigados. Observaram também que, em geral, o professor mal dispõe de tempo para ministrar a própria disciplina, pois se encontra sempre sobrecarregado de inúmeros afazeres.

Interrogadas a respeito dos principais problemas nas formas de ensinar e aprender no curso de Pedagogia, $60 \%$ das alunas responderam que 
as maiores dificuldades incidem sobre a prática pedagógica dos professores: seleção de conteúdos, metodologia, avaliação e relações antidemocráticas entre professor e aluno.

De acordo com uma das entrevistadas,

é muito difícil a relação entre determinados professores e alunos. A maioria chega com seu plano de ensino fechado, enumera os inúmeros conteúdos (muitas vezes conteúdos que nada têm a ver com a nossa vida, com a nossa realidade), impõe uma metodologia e diz como será a avaliação sem, ao menos, consultar nossa opinião. [E destacou:] Teve professor que dava vários conteúdos todos os dias para fazermos sínteses e expor no dia seguinte. O pior é que junto com a tarefa, vinha a ameaça de nota baixa para quem não fizesse.

Outra aluna entrevistada se manifestou na mesma perspectiva:

Obtive algum aprendizado nessa disciplina, mas a metodologia desse professor foi muito estressante, pois ele não dava tempo para lermos o material com calma e atenção e todos os dias do módulo tinha um seminário e uma avaliação. Não tínhamos tempo para assimilar tanta coisa de um dia para o outro.

Tais relatos evidenciam causas de sérios problemas que se enfrentam no dia a dia nas escolas públicas em geral e, especialmente, no curso de Pedagogia da UFMT, a saber, o visível desconforto com as relações de poder e controle em sala de aula e o visível desinteresse, indiferença e desmotivação por parte da quase totalidade dos estudantes no processo educativo.

A desmotivação é a maneira pela qual o estudante mostra a sua recusa ao currículo oficial. Na universidade, os conceitos estudados podem contribuir para desvincular a formação intelectual da realidade. Trabalhamos uma série de conteúdos sem a necessária ligação com o contexto em que vivemos. É como se houvessem dois mundos, o mundo intelectual onde reina o "balé de conceitos" e o mundo da experiência na realidade concreta. A pedagogia oficial estimula o estudante contra o trabalho intelectual de produção criativa de conhecimento. O currículo oficial impõe o estudo de textos, aulas expositivas, provas como exercício de submissão à autoridade e o estudante revela sua resistência de diversas formas a esse modelo de educação: em forma de imobilismo, ironia, ausências da sala, rebeldia, silêncio excessivo, conversas demasiadas. (FREIRE \& SHOR, 1986, p. 23)

Outra aluna entrevistada, ao relatar sua experiência, complementou:

O professor costuma desenvolver um sem-número de conteúdo, depois faz avaliação e dá a nota. Salvo raras exceções, o professor não explica o que se 
errou na avaliação e, consequentemente, porque se tirou nota A, B ou C; e a nota é muito importante para nosso currículo e profissão, porque os alunos que se sobressaem e conseguem melhores avaliações (a partir de 7.0) são premiados com bolsas de diversas modalidades, e aqueles que não alcançam tais valores são punidos com a exclusão delas.

Decerto, o sistema disciplinar permite ao professor controlar o aluno tanto pela via pedagógica (verificando seu saber e sua aprendizagem) quanto pela via do comportamento, na medida que quantifica e mensura tal aprendizagem na perspectiva de uma premiação ou punição. Isso tende a alimentar a educação competitiva, uma vez que se preocupa em escolher e premiar aqueles que não precisam de reforço, em detrimento daquele que merece mais atenção. "A educação competitiva gera consequências nocivas para a aprendizagem, pois o aluno tende a se preocupar mais com a nota, certificado e diploma do que com a produção de conhecimentos" (TRAGTENBERG, 2004, p. 72).

Por outro lado, $40 \%$ das alunas afirmaram haver professores que nutrem uma boa relação com os alunos e, até, discutem como será a avaliação da disciplina. Veja a seguir relatos de algumas entrevistadas:

Também há professores que adotam relações democráticas em sala de aula, que escutam o que a gente tem pra dizer, são compreensivos.

Gostei muito da metodologia de dois professores, dos autores e materiais selecionados e estudados nas aulas. Nesses módulos, houve interações entre professor e aluno, entre colegas. Havia conversa e discussão sobre os problemas, pois, até então, o estranhamento era fortíssimo entre as partes, com pouca comunicação e muitos desencontros entre nós.

Teve mais outro professor que desenvolveu a disciplina de forma bem tranquila, ficamos bem à vontade, tive um ótimo desempenho na avaliação realizada.

Esperamos que a narrativa dessa experiência possa se tornar fecunda, no sentido de contribuir para estimular a criatividade de quantos trabalham visando a melhoria da produtividade do conhecimento, do ensino e das relações entre educador-educando nos espaços escolares.

\section{ESTRATÉGIAS PARA INVERTER O MOVIMENTO DISCIPLINAR NA EDUCAÇÃO}

A partir da percepção desta pesquisadora e das informações colhidas das alunas entrevistadas, constataram-se algumas questões principais: a presença de professores que, embora em número reduzido e sem articulação, 
procuram desenvolver conteúdos e relações pedagógicas de forma interdisciplinar; a ausência de sensibilização e disponibilidade ao diálogo por parte da maioria do corpo docente e desmotivação das alunas em relação aos conteúdos curriculares e aos dispositivos disciplinares na instituição escolar.

De fato, a maioria dos professores não se mostrou sensível ao trabalho interdisciplinar e o resultado não poderia ser exitoso, uma vez que, sem diálogo, qualquer iniciativa de prática pedagógica inovadora cai no vazio e perde o sentido que deriva da articulação mais geral da parte com o todo. A falta de diálogo entre os sujeitos torna irrealizável a ação interdisciplinar, porque inviabiliza o sentido da interdependência entre tudo e todos e, assim, mina a concretização da democracia pelo individualismo e autismo.

Não se quer dizer com isso que inexistem conversas entre professores e entre professores e alunos. Quer-se dizer, sim, que grande parte do corpo docente mostra-se resistente à abertura de horizontes para a construção de um trabalho interdisciplinar, dado que o conhecimento pretensamente sistematizado para "ser servido ao ponto" é suficiente por si mesmo, sem necessidades de articulações mais gerais.

Observou-se, também, que a racionalidade disciplinar na universidade cerceia o desenvolvimento da ação dialógica entre os docentes, na medida que as propostas pedagógicas - que visam rompimento das fronteiras disciplinares e implicam trabalho coletivo - são quase sempre pensadas e elaboradas em seus conteúdos e metodologias por um seleto grupo de professores e, posteriormente, apresentadas e difundidas pelos poderes pedagógicos para sua aplicação.

Desse modo, é difícil reverter o aprisionamento disciplinar e propiciar um trabalho educativo democrático e emancipatório, pois a relação entre os docentes reproduz, como algo "natural", a divisão social e técnica do trabalho; isso é, divide os docentes entre os capacitados para pensar, elaborar e planejar as propostas pedagógicas e os que são habilitados para a sua execução.

Nessa condição, a maioria dos docentes não se sente estimulada a se envolver com o trabalho coletivo, uma vez que não é convidada a participar de todas as suas etapas. Ao invés de mostrar-se receptiva e disposta a realizar a proposta, surge, ainda mais vigorosa, a resistência (às vezes explícita, às vezes silenciosa) a ela, e o resultado do trabalho educativo, que deveria ser assumido coletivamente, se reduz, quando muito, em um esforço solitário (como nesta pesquisa), isolado, contraditório.

A construção de ações interdisciplinares e democráticas - no ambiente escolar, em geral, e na universidade, em particular - implica desenvolver estratégias de diálogo que superem os mecanismos da racionalidade disci- 
plinar. Tais ações são muito difíceis, complexas e desafiadoras, pois implicam mudanças profundas na organização e nas relações entre educadores e educandos. A ideia é que o professor investido no poder pedagógico (coordenador do curso e não de série) busque a colaboração de seus pares para o trabalho conjunto de planejamento, execução e avaliação da ação educativa.

Sabe-se, contudo, que tal colaboração não é fácil de ser conquistada, sobretudo porque o professor vive sobrecarregado de encargos pedagógicos e burocráticos, tanto no que se refere ao ensino de graduação quanto de pósgraduação (pesquisa, ensino, orientação, produção bibliográfica, participação em eventos, relatórios, exaustivas reuniões, comissões etc.). Além disso, a ação interdisciplinar exige trabalho contínuo e partilhado dos professores assim como o abandono de hábitos arraigados, fortemente marcados pelo individualismo - e, ainda, requer empenho profundo, compromisso éticopolítico e paciência histórica com as contradições do processo.

Outro aspecto constante nos relatos das alunas entrevistadas diz respeito às relações disciplinares entre educadores-educandos. Por isso, considera-se importante tentar construir relações educativas, não a partir das relações de poder fundadas na hierarquia e controle (conforme explica Tragtenberg) e nem a partir da "educação bancária", acrítica (no sentido freiriano), mas provocar a vivência da relação intersubjetiva entre as pessoas. Isso significa que a relação não pode ocorrer unidirecional e verticalizada, mas de forma recíproca, em que todos possam se manifestar enquanto sujeito.

A relação dialógica implica superar a relação que converte o outro em objeto. A verdadeira relação dialógica reivindica um saber como arte de explorar condições favoráveis para fazer com que o educando manifeste sua subjetividade, aflore sua consciência crítica e se converta em um ser plenamente humano. Nessa perspectiva, é necessário estimular o educando a abandonar a cultura do silêncio, a denunciar os fundamentos da relação desigual e injusta, pois o diálogo verdadeiro supõe o encontro de sujeitos que atuam no mundo social e pedagógico, ancorados na palavra, no trabalho, na ação-reflexão para refletir sobre como constroem e reconstroem o mundo, sobre como constroem e reconstroem a ação educativa. (FREIRE, 2005, p. 91)

No ato de construção e reconstrução da ação educativa, considerase imprescindível o conhecimento crítico da realidade, não a partir da ideia de que a história é feita pela atuação e desempenho de quem está no poder (típico da educação bancária), mas trazer ao debate, como problema, a própria história do educando: sua situação existencial concreta, seus sonhos, suas lutas, suas dores, seus problemas (de saúde, moradia, transporte, violência visível e sutil), tragédias que compõem a realidade do dia a dia, sua situação de classe, sua condição de oprimido. 
A educação freiriana é muito interessante no sentido de possibilitar ao educando conhecer a realidade e libertar-se da opressão. Quem sabe, dessa forma, o educando passe de "objeto" a sujeito da relação pedagógica e passe da desmotivação à participação em sala de aula, já que o conteúdo curricular, uma vez refletido a partir de sua própria vivência que desvela o real, o concreto, o vivido - e uma vez que transforma a experiência vivida em experiência compreendida - passa a interferir de forma consciente na realidade, para transformá-la.

De qualquer modo, compreende-se que a teoria pedagógica em si (por mais emancipadora que seja) pode ser trabalhada tanto para libertar quanto para disciplinar. O mais importante é enfrentar os problemas e as contradições do processo pedagógico de forma verdadeira. A construção de relações dialógicas e democráticas só se dará na crítica e na autocrítica, na criação e recriação, com erros e acertos, seja com relação ao conhecimento, seja com relação às relações acadêmicas, donde as bases de ambos envolvam flexibilidade, predisposição ao diálogo. "Sem ele não há comunicação e sem essa não há verdadeira educação" (FREIRE, 2005, p. 96).

\section{DIALOGICAL PEDAGOGICAL ACTION:THE CHALLENGE TO OVERCOMMING SUBJECT RATIONALITY}

ABSTRACT: This article presents results of a research on a possible implementation of interdisciplinary educational action in the Pedagogy undergraduate course. After the introduction, it briefly revisits Weber and Tragtenberg's theoretical statements concerning the process of modern rationalization and its implications for education through the teaching of individualized subjects. Using a phenomenological qualitative investigation, it presents information collected from the students interviewed and as a result, it understands and explains that it is very difficult to build interdisciplinary pedagogical action at the heart of an institution which teaches through the system of individualized subjects. It concludes with a brief synthesis of the research analysis and points out strategies for inverting the movement of teaching individualized subjects.

KEYWORDS: Subject rationality. Bureaucratic pedagogy. Interdisciplinarity. Dialogical pedagogical actions.

\section{ACCIÓN PEDAGÓGICA DIALÓGICA: UN DESAFÍO PARA SUPERAR LA RACIONALIDAD DISCIPLINAR}

RESUMEN: El trabajo presenta los resultados de la investigación sobre la posibilidad de hacer efectiva la acción educativa de cuño interdisciplinar en el curso de Pedagogía. Después de la introducción, se retoma resumidamente las indicaciones teóricas de 
Weber y Tragtenberg sobre el proceso de racionalización moderno y sus implicaciones en la educación disciplinar. Con base en la investigación cualitativa fenomenológica, se describen las informaciones obtenidas de las alumnas entrevistadas y como resultado se comprende e interpreta que es muy difícil construir la acción pedagógica de cuño interdisciplinar en el interior de la institución anclada en la disciplinariedad. Se finaliza, presentando una breve síntesis del análisis de la investigación y se apuntan estrategias para invertir el movimiento disciplinar en la educación.

PALABRAS-CLAVES: Racionalidad disciplinar. Pedagogía burocrática. Interdisciplinariedad. Acciones pedagógicas dialógicas.

\section{REFERÊNCIAS}

BICUDO, M. A. V.; ESPÓSITO, V. H. C. Pesquisa qualitativa em educação. 2. ed. Piracicaba: Unimep, 1997.

BOGDAN, R.; BIKLEN, S. K. Investigação qualitativa em educação, uma introdução à teoria e aos métodos. Trad. Maria João Álvares, Sara Bahia dos Santos, Telmo Mourinho Baptista. Portugal: 1984.

FAZENDA, I. C. A. Integração e interdisciplinaridade no ensino brasileiro: efetividade ou ideologia. São Paulo: Loyola, 1979.

FAZENDA, I. C. A. (Org.). Práticas interdisciplinares na escola. São Paulo: Cortez, 1991.

FAZENDA, I. C. A. Interdisciplinaridade: história, teoria e pesquisa. Campinas: Papirus, 1994.

FREIRE, P. Pedagogia do oprimido. 45. ed. Rio de Janeiro: Paz e Terra, 2005.

FREIRE, P; SHOR, I. Medo e ousadia - o cotidiano do professor. Trad. Adriana Lopez. 9. ed. Rio de Janeiro: Paz e Terra, 1986.

FREITAS, L. C. A questão da interdisciplinaridade. Notas para a reformulação dos cursos de Pedagogia. Educação \& Sociedade, São Paulo, n. 33, 1989.

FRIGOTTO, G. A interdisciplinaridade como necessidade e como problema das ciências sociais. In: JANTSCH, A. P.; BIANCHETTI, L. (Org.). Interdisciplinaridade: para além da filosofia do sujeito. Petrópolis: Vozes, 1995.

GADOTTI, M. A organização do trabalho na escola: alguns pressupostos. São Paulo: Ática, 1993.

GALLO, S. Educação e interdisciplinaridade. Revista de Educação, Campinas: Sinpro, n. 1, 1994.

GALLO, S. Saberes, transversalidade e poderes. Revista de Educação, Salvador: CEAP, n. $15,1996$.

GONÇALVES, M. A. S. Interdisciplinaridade e educação básica. Algumas reflexões introduções. In: Educação básica e o básico em educação. Porto Alegre: Sulina, 1996. 
GUSDORF, G. La parole. Paris: Presses Universitaires de France, 1953.

JANTSCH, A. P.; BIANCHETTI, L. (Org.). Interdisciplinaridade: para além da filosofia do sujeito. Petrópolis: Vozes, 1995.

JAPIASSU, H. Interdisciplinaridade e patologia do saber. Rio de Janeiro: Imago, 1976.

LÜCK, H. Pedagogia interdisciplinar: fundamentos teórico-metodológicos. Petrópolis: Vozes, 1994.

LÜDKE, M.; ANDRÉ, M. E. D. A. Pesquisa em educação: abordagens qualitativas. São Paulo: EPU, 1986.

MARTINS, J. et al. Temas fundamentais de fenomenologia. São Paulo: Moraes, 1984.

MERLEAU-PONTY, M. Fenomenologia da percepção. Trad. Reginaldo di Piero. Rio de Janeiro: Freitas Bastos, 1971.

MORAES, M. C. O paradigma educacional emergente. São Paulo: Papirus, 2002.

MORIN, E. Educação e complexidade, os sete saberes e outros ensaios. São Paulo: Cortez, 2005.

PIAGET, J. Para onde vai a educação? Rio de Janeiro: José Olympio, 1973.

POMBO, O. Interdisciplinaridade: conceito, problema e perspectiva. In: A interdisciplinaridade: reflexão e experiência. Lisboa: Universidade de Lisboa, 1993.

POMBO, O. Interdisciplinaridade: conceito, problema e perspectiva. In: A interdisciplinaridade: reflexão e experiência. Lisboa: Universidade de Lisboa, 1993. Disponível em: http://www.educ.fc.ul.pt/docentes/pombo/mathesis/interdisciplinaridade.pdf. Acesso em: 14 dez. 2003.

POMBO, O. Interdisciplinaridade. Ambições e limites. Lisboa: Relógio d’Água, 2004.

REZENDE, A. M. Concepção fenomenológica da educação. São Paulo: Cortez e Autores Associados, 1990.

SOUZA, N. M. Modernidade: a estratégia do abismo. 2. ed. Campinas: Editora Unicamp, 1999.

TRAGTENBERG, M. Sobre educação, política e sindicalismo. 3. ed. São Paulo: Editora Unesp, 2004.

THIESEN, J. S. A interdisciplinaridade como um movimento articulador no processo ensino-aprendizagem. Revista Brasileira de Educação, v. 13, n. 39, set-dez. 2008.

VYGOTSKY, L. Pensamiento y lenguaje. Buenos Aires: La Pléyade, 1986.

WEBER, M. Economia e sociedade: fundamentos da sociologia compreensiva. Trad. Regis Barbosa e Karen Elsabe Barbosa. 3. ed. Brasília: EdUnB, 1994/1999. v. I e II.

WEBER, M. A Ética protestante e o espírito do capitalismo. Trad. Ana Maria Falcão e Luís Leitão. Lisboa: 2001. 
Maria da Anunciação PInheiro Barros Neta: licenciada em Filosofia pela Universidade Federal do Maranhão (UFMA); mestre em Educação na área de História e Filosofia da Educação pela Universidade de São Paulo (USP); doutora em Educação na área de História, Filosofia e Educação pela Universidade Estadual de Campinas (Unicamp); atua como docente, desde 1994, no Departamento de Teoria e Fundamentos da Educação da Universidade Federal de Mato Grosso-IE-UFMT, no curso de Pedagogia e no Programa de Pós-Graduação em Educação (PPGE).

E-mail:barrosneta@smail.com 